\title{
Quantitative Analysis of Somatostatin and Dopamine Receptors Gene Expression Levels in Non-Functioning Pituitary Tumors and Association with Clinical and Molecular Aggressiveness Features
}

\author{
Álvaro Flores-Martinez ${ }^{1}$ (D), Eva Venegas-Moreno ${ }^{1}$, Elena Dios ${ }^{1}$, Pablo Remón-Ruiz ${ }^{1}$, \\ Noelia Gros-Herguido ${ }^{1}$, M. Carmen Vázquez-Borrego ${ }^{2,3,4,5}$, Ainara Madrazo-Atutxa ${ }^{1}$, \\ Miguel A. Japón ${ }^{6}{ }^{\mathbb{D}}$, Ariel Kaen ${ }^{7} \mathbb{D}$, Eugenio Cárdenas-Valdepeñas ${ }^{7}$, Florinda Roldán ${ }^{8}$, \\ Justo P. Castaño ${ }^{2,3,4,5}$, Raúl M. Luque ${ }^{2,3,4,5}$, David A. Cano ${ }^{1, * \mathbb{D}}$ and Alfonso Soto-Moreno ${ }^{1, *}$ \\ 1 Unidad de Gestión de Endocrinología y Nutrición, Instituto de Biomedicina de Sevilla (IBiS), \\ Hospital Universitario Virgen del Rocío/CSIC/Universidad de Sevilla, 41013 Sevilla, Spain; \\ alvflomar@gmail.com (Á.F.-M.); evam.venegas.sspa@juntadeandalucia.es (E.V.-M.); \\ elenadiosfuentes@gmail.com (E.D.); pjremonruiz@gmail.com (P.R.-R.); ngros.h@gmail.com (N.G.-H.); \\ amadrazoatutxa@gmail.com (A.M.-A.) \\ 2 Maimonides Institute for Biomedical Research of Córdoba (IMIBIC), 14004 Córdoba, Spain; \\ marvazbor@gmail.com (M.C.V.-B.); justo@uco.es (J.P.C.); bc2luhur@uco.es (R.M.L.) \\ 3 Department of Cell Biology, Physiology and Immunology, University of Córdoba, 14004 Córdoba, Spain \\ 4 Hospital Universitario Reina Sofía, 14004 Córdoba, Spain \\ 5 CIBER Fisiopatología de la Obesidad y Nutrición (CIBERObn), 14004 Córdoba, Spain \\ 6 Department of Pathology, Hospital Universitario Virgen del Rocío, Instituto de Biomedicina de Sevilla (IBIS), \\ Hospital Universitario Virgen del Rocío/CSIC/Universidad de Sevilla, 41013 Sevilla, Spain; \\ mangel.japon.sspa@juntadeandalucia.es \\ 7 Servicio de Neurocirugía, Hospital Universitario Virgen del Rocío, 41013 Sevilla, Spain; \\ kaenariel@hotmail.com (A.K.); eugeniocarde@hotmail.com (E.C.-V.) \\ 8 Servicio de Radiología, Hospital Universitario Virgen del Rocío, 41013 Sevilla, Spain; florivict@gmail.com \\ * Correspondence: dcano-ibis@us.es (D.A.C.); alfonsom.soto.sspa@juntadeandalucia.es (A.S.-M.)
}

Received: 4 August 2020; Accepted: 7 September 2020; Published: 22 September 2020

check for updates

\begin{abstract}
The primary treatment for non-functioning pituitary tumors (NFPTs) is surgery, but it is often unsuccessful. Previous studies have reported that NFPTs express receptors for somatostatin $\left(\mathrm{SST}_{1-5}\right)$ and dopamine (DRDs) providing a rationale for the use of dopamine agonists and somatostatin analogues. Here, we systematically assessed $\mathrm{SST}_{1-5}$ and DRDs expression by real-time quantitative PCR (RT-qPCR) in a large group of patients with NFPTs $(n=113)$ and analyzed their potential association with clinical and molecular aggressiveness features. $\mathrm{SST}_{1-5}$ expression was also evaluated by immunohistochemistry. $\mathrm{SST}_{3}$ was the predominant SST subtype detected, followed by $\mathrm{SST}_{2}, \mathrm{SST}_{5}$, and $\mathrm{SST}_{1}$. DRD2 was the dominant DRD subtype, followed by DRD4, DRD5, and DRD1. A substantial proportion of NFPTs displayed marked expression of $\mathrm{SST}_{2}$ and $\mathrm{SST}_{5}$. No major association between $\mathrm{SST}_{\mathrm{S}}$ and DRDs expression and clinical and molecular aggressiveness features was observed in NFPTs.
\end{abstract}

Keywords: pituitary tumor; invasion; somatostatin receptor; dopamine receptor; non-functioning pituitary tumors

\section{Introduction}

Non-functioning pituitary tumors (NFPTs) are characterized by the absence of clinical symptoms related to pituitary hormone overproduction. NFPTs usually present with symptoms related to mass 
effects such as visual impairment, headaches and hypopituitarism [1]. Histologically, NFPTs comprise a heterogeneous group of tumors, consisting of gonadotropin-storing tumors, silent pituitary tumors and null cell adenomas. NFPTs are usually benign but a substantial proportion of these pituitary tumors show an aggressive behavior with local invasion, and increased risk of regrowth or recurrence after surgery $[2,3]$. However, the underlying mechanisms for this aggressive behavior are largely unknown $[4,5]$. The primary line of treatment for these tumors is transsphenoidal resection but it is often surgically incomplete and/or clinically unsuccessful [6]. Currently, there is no medical therapy approved for the treatment of NFPTs [7,8]. NFPTs express dopamine receptors (DRDs) and several studies have described the use of dopamine agonists for the treatment of NFPT patients, albeit with variable success [7-9]. NFPTs also express somatostatin receptors $\left(\mathrm{SST}_{1-5}\right)$ thus providing a theoretical rationale for the pharmacological treatment with somatostatin analogues [10]. However, in the limited number of studies published to date, SSTs expression has been analyzed at the mRNA level [11-13] or by immunohistochemistry (IHC) $[14,15]$ but rarely both methods have been applied simultaneously in the same study. This is an important point, as a consistent method for evaluating SST $_{1-5}$ expression in pituitary tumors has yet to be implemented in a clinical pathology setting.

Several immunohistochemical biomarkers have been studied for their potential association to aggressive features in NFPTs such as the Ki-67 proliferative index, p53 and ER $\alpha$ (recently reviewed in [16]). However, more studies are needed to firmly establish their utility in clinical practice.

The aim of this study was to thoroughly analyze DRDs and SSTs expression in a cohort of well-characterized NFPT samples by both real-time quantitative PCR (RT-qPCR) and immunohistochemistry (IHC). In addition, we aim to determine the potential association of DRDs and SSTs expression with relevant clinical and molecular aggressive features of NFPTs.

\section{Experimental Section}

\subsection{Patients and Samples}

This study was conducted following the ethical standards of the Helsinki Declaration of the World Medical Association and approved by the IBiS-Virgen del Rocio Hospital Ethics Committee (0208-N-17) and written informed consent was obtained from all patients. The biobank of the public health system of Andalusia, Spain (Seville Node) coordinated the collection, processing, management and assignment of the biological samples used in this study, according to the standard procedures established for this purpose. This retrospective descriptive study includes patients diagnosed with NFPTs who underwent transsphenoidal surgery for newly or recurrent pituitary tumors by the same team of neurosurgeons at the Virgen del Rocío University Hospital (Seville, Spain) between 1998 and 2017. Patients were evaluated by a multidisciplinary team composed of neuroradiologists, neurosurgeons, and endocrinologists. The initial diagnosis of NFPT was established based on the absence of biochemical hormonal overproduction and lack of associated clinical symptoms. After surgery, the diagnosis was verified histologically and immunohistochemically for pituitary hormones (Growth hormone, prolactin, adrenocorticotropic hormone, luteinizing hormone, follicle-stimulating hormone and thyroid-stimulating hormone) by an experienced pathologist. One hundred and thirteen patients whose archival tissues were available were included in this study. Clinical variables were collected to analyze potential associations between these variables and DRDs and SSTs expression. Specifically, cavernous sinus invasion and tumor size data were acquired from magnetic resonance images. Cavernous sinus invasion was evaluated using the Knosp classification. Knosp grade 3 and 4 were considered invasive. Surgical cure was defined as absence of tumor on MRI at 3 months after surgery. Tumor regrowth was defined as evidence of regrowth of tumor remnant on MRI within 2 years of follow-up. 


\subsection{Histopathology and Immunohistochemistry}

Formalin-fixed paraffin-embedded tissues from NFPTs were obtained and four tissue microarrays (TMAs) were constructed. Cores were taken from areas of the paraffin block recognized as tumor tissue by evaluation of hematoxylin and eosin-stained sections by an expert pathologist. Duplicates of each NFPTs and four cores of normal pituitary tissue (obtained from autopsies) were included in each TMA. SSTs and E-cadherin immunohistochemistry as well as the used score system has been previously described $[17,18]$. DRD expression was not evaluated since, to the best of our knowledge, no commercial reliable antibodies are available. The following SSTs antibodies were used: $\mathrm{SST}_{2}$ (Abcam, Cambridge, UK, ab134152) 1:100; SST $_{3}$ (Abcam, Cambridge, UK, ab137026) 1:750; SST 5 (Abcam, Cambridge, UK, ab109495) 1:100. Immunohistochemical analysis for E-cadherin (ready-to-use, clone 36, VENTANA, Roche, Basel, Switzerland, catalog number 790-4497), Ki-67 (clone 30-9, VENTANA, Roche, Basel, Switzerland, catalog number 790-4286), and p53 (clone DO-7, VENTANA, Roche, Basel, Switzerland, catalog number 790-2912) were performed using an automated immunostainer system (VENTANA, Roche, Basel, Switzerland) following the manufacturer's specifications. Ki-67 index was determined as the percentage of tumor cells with nuclei positive for Ki-67 in relation to total cells in at least 3 different spots.

\subsection{RNA Isolation, Reverse Transcription, and Analysis of Gene Expression by Quantitative Real-Time PCR}

Somatostatin receptor ( $\mathrm{SST}_{1}-\mathrm{SST}_{5}$ ) and dopamine receptor (DRD1-DRD5) expression by real-time quantitative PCR (RT-qPCR) was quantified using primers previously reported [19]. $\mathrm{SST}_{4}$ and DRD3 were not analyzed since their expression is negligible in NFPTs $[10,11,20]$. The expression values of target genes were normalized to ACTB mRNA levels, as in previous studies from our group [21,22]. Technical details on RNA extraction, reverse-transcription and qPCR quantification have been reported elsewhere [18,23].

\subsection{Statistical Analysis}

Normality of the data was assessed using the Kolmogorov-Smirnov test. The categorical variables are described as percentages and frequencies. Non-normally distributed data are shown as median values with interquartile ranges (IQR). For normally distributed mean $\pm \mathrm{SD}$ are shown. ANOVA and Student's t test were used for parametric variables and Kruskal-Wallis and Mann-Whitney test for nonparametric variables. Chi-square was used for categorical variables. Spearman's rank correlation coefficient was used for correlation analysis between continuous variables. $\mathrm{P}$ values were adjusted for multiple comparisons by the Benjamini-Hochberg false discovery rate method. Statistical analysis was performed using SPSS software version 25.0 for Windows (SPSS, Chicago, IL, USA). $p$ values $<0.05$ were considered statistically significant.

\section{Results}

\subsection{Patient and Sample Characteristics}

A total of 113 NFPTs tumors from patients were analyzed. The clinical characteristics of the study population are shown in Table 1. All of the patients with NFPT had macroadenomas. Fifty-two tumors $(46 \%)$ were invasive. Only four tumors had high Ki-67 levels ( $>3 \%)$. Thirty-two tumors $(28.3 \%)$ did not show any hormonal expression, as assessed by immunohistochemistry (Table 2). Surgery achieved complete resection in 41 patients (36.3\%). Tumor regrowth within two years of follow-up was observed in $15 \%$ of the patients (17 out of 58 ) with tumor remnant after surgery. 
Table 1. Baseline characteristics of the study populations. IQR: interquartile ranges.

\begin{tabular}{cc}
\hline Characteristics & \\
\hline Sex (number and \% female) & $40(35.4)$ \\
Age at diagnosis (years, median, IQR) & $58(44-70.5)$ \\
Maximum tumor diameter at diagnosis (mm, median, IQR) & $29.5(22-39.5)$ \\
Invasiveness (\% Knosp grade $\geq 3)$ & $52(46)$ \\
Ki-67 index (\%, median, IQR) & $0.54(0.30-1.05)$ \\
\hline
\end{tabular}

Table 2. Non-functioning pituitary tumors (NFPTs) histological subtypes.

\begin{tabular}{cc}
\hline Histological Subtype & Number (\%) \\
\hline Gonadotroph-storing tumor & $67(59.3)$ \\
Null cell tumor & $32(28.3)$ \\
Silent corticotroph tumor & $10(8.8)$ \\
Plurihormonal tumor & $2(1.8)$ \\
Silent somatotroph tumor & $2(1.8)$ \\
\hline
\end{tabular}

\subsection{Receptor Expression Levels in NFPTs}

Mean mRNA expression levels of SSTs and DRDs from NFPTs are shown in Figure $1 \mathrm{~A}$. $\mathrm{SST}_{3}$ was the predominant SST subtype detected, followed by $\mathrm{SST}_{2}, \mathrm{SST}_{5}$, and $\mathrm{SST}_{1}$. DRD2 was the dominant DRD subtype, followed by DRD4, DRD5, and DRD1 (Figure 1A). Expression levels for the major histopathological types of NFPTs (i.e. Gonadotropin-storing tumors; $(n=67)$, null cell tumors $(n=32)$ and silent corticotroph tumors $(n=10)$ ) are also shown in Figure 1 (only two plurihormonal and two silent Growth Hormone-storing tumors were found in our cohort).

A

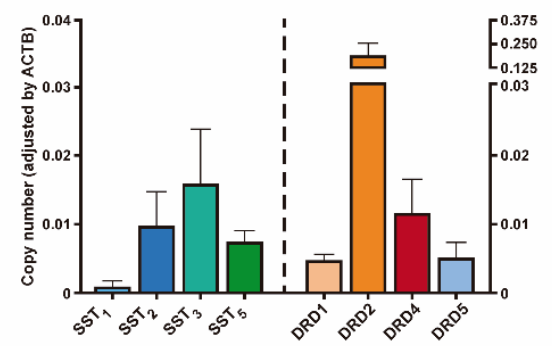

C

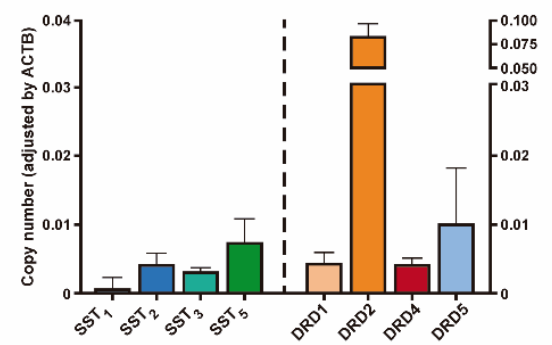

B

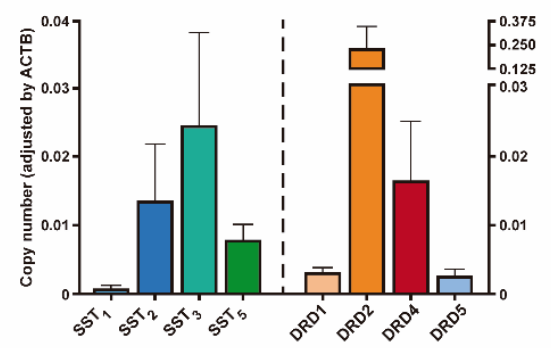

D

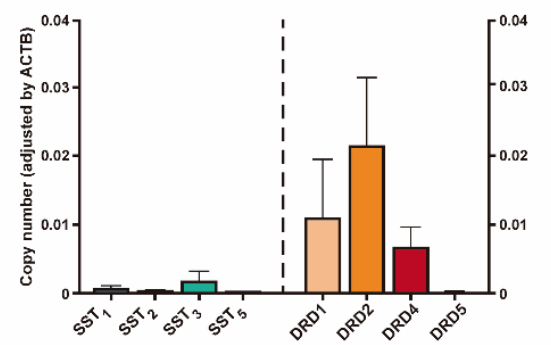

Figure 1. Somatostatin receptors (SSTs) and dopamine receptors (DRDs) expression in NFPTs. Expression profile of SSTs and DRDs in: (A) NFPTs, gonadotropin-storing adenomas, null cell adenomas and silent corticotroph adenomas; (B) only in gonadotropin-storing adenomas; (C) only in null cell adenomas; and, (D) only in silent corticotroph adenomas. mRNA expression levels were measured by quantitative RT-PCR. Copy numbers of each transcript was adjusted by the expression levels of a control gene (ACTB). Data are shown as mean \pm SEM. 
Gonadotropin-storing tumors show an expression pattern similar to what it is observed in the whole NFPT population, with $\mathrm{SST}_{3}$ and DRD2 displaying the highest expression levels (Figure 1B). Null cell adenomas (defined as tumors lacking any immunohistochemical hormone expression), however, display a different SSTs and DRDs expression pattern, with $\mathrm{SST}_{5}$ being the predominant SST subtype expressed, followed by $\mathrm{SST}_{2}, \mathrm{SST}_{3}$ and $\mathrm{SST}_{1}$, while DRD2 was the dominant DRD subtype, followed by DRD5, DRD1 and DRD4 (Figure 1C). Silent corticotroph tumors (SCTs) are defined as pituitary tumors with immunohistochemical expression of ACTH but without biochemical hypercortisolism and no clinical symptoms of Cushing's disease. SCTs are considered aggressive pituitary tumors [24]. In SCTs, SST expression was, in general, low. SST $_{3}$ showed the highest expression, but levels were notably lower compared to gonadotropin-storing tumors and null cell tumors. DRD expression pattern in SCTs was also different compared to the other two major histological subtypes, being DRD2 the predominant DRD subtype followed by DRD1, and DRD4. Notably, DRD5 expression levels were extremely low (Figure 1D).

In NFPTs, expression levels of $\mathrm{SST}_{2}$ were directly correlated to $\mathrm{SST}_{1}(r=0.34$, Spearman FDR adjusted $p=0.015), \operatorname{SST}_{3}(r=0.31, p=0.008)$ and $\mathrm{SST}_{5}(r=0.35, p=0.015) . \mathrm{SST}_{1}$ expression levels were directly correlated to $\mathrm{SST}_{5}(r=0.35, p=0.015)$. Expression levels of DRD1 were directly correlated with DRD5 expression levels $(r=0.33, p=0.018)$. In addition, several significant correlations were found between SSTs and DRDs. Specifically, $\mathrm{SST}_{1}$ expression levels were directly correlated to DRD1 $(r=0.35, p=0.015)$ and DRD5 expression levels $(r=0.33, p=0.018)$. $\mathrm{SST}_{2}$ expression levels were directly correlated to DRD5 expression levels $(r=0.43, p=0.001)$. Expression levels of $\mathrm{SST}_{3}$ were directly correlated to those of DRD2 $(r=0.36, p=0.001)$. SST 5 expression levels were directly correlated to DRD4 $(r=0.29, p=0.04)$ and DRD5 expression levels $(r=0.38, p=0.008)$.

\subsection{Association between Clinical Characteristics of NFPTs and SSTs or DRDs mRNA Levels}

We evaluated whether there was an association between SSTs or DRDs mRNA expression levels and key clinical features of aggressiveness in NFPTs. However, no significant differences were found between invasion, surgical cure or tumor regrowth and expression levels of any SST and DRD receptor. Additionally, no significant correlations between SSTs or DRDs expression and tumor size, age or sex was observed. We performed the same analysis in two histological groups of NFPTs: gonadotropin-storing tumors and null cell adenomas (the number of SCTs in our series was too low to make meaningful analyses). Specifically, no significant differences were found between invasion, surgical cure or tumor regrowth and expression levels of any SST and DRD receptor in gonadotropin-storing tumors and null cell adenomas. However, in gonadotropin-storing tumors we observed a negative correlation between DRD2 expression and tumor size $(r=-0.36, p=0.03)$, while in null cell adenomas, a positive correlation was found between DRD5 mRNA expression and tumor size $(r=0.66, p=0.004)$. Of note, no difference in the gene expression level of any SSTs and DRDs was found between gonadotropin-storing tumors and null cell adenomas.

\subsection{SSTs Expression in NFPTs as Assessed by Immunohistochemistry}

Evaluation of SSTs expression by IHC, while perhaps less sensitive, is very useful in the clinical setting. We decided to evaluate SSTs expression with commercial antibodies that have been previously used in several studies, including from our own group. Of the 113 NFPTs included in the study, we could analyze SSTs expression by IHC in 95 . We were unable to obtain reliable immunoreactivity with the $\mathrm{SST}_{1}$ antibody (Abcam, ab137083) in any NFPT sample and thus, IHC scoring was not performed for $\mathrm{SST}_{1}$. Representative images of SSTs in normal pituitary and the different scores in NFPTs are shown in Figure 2. 

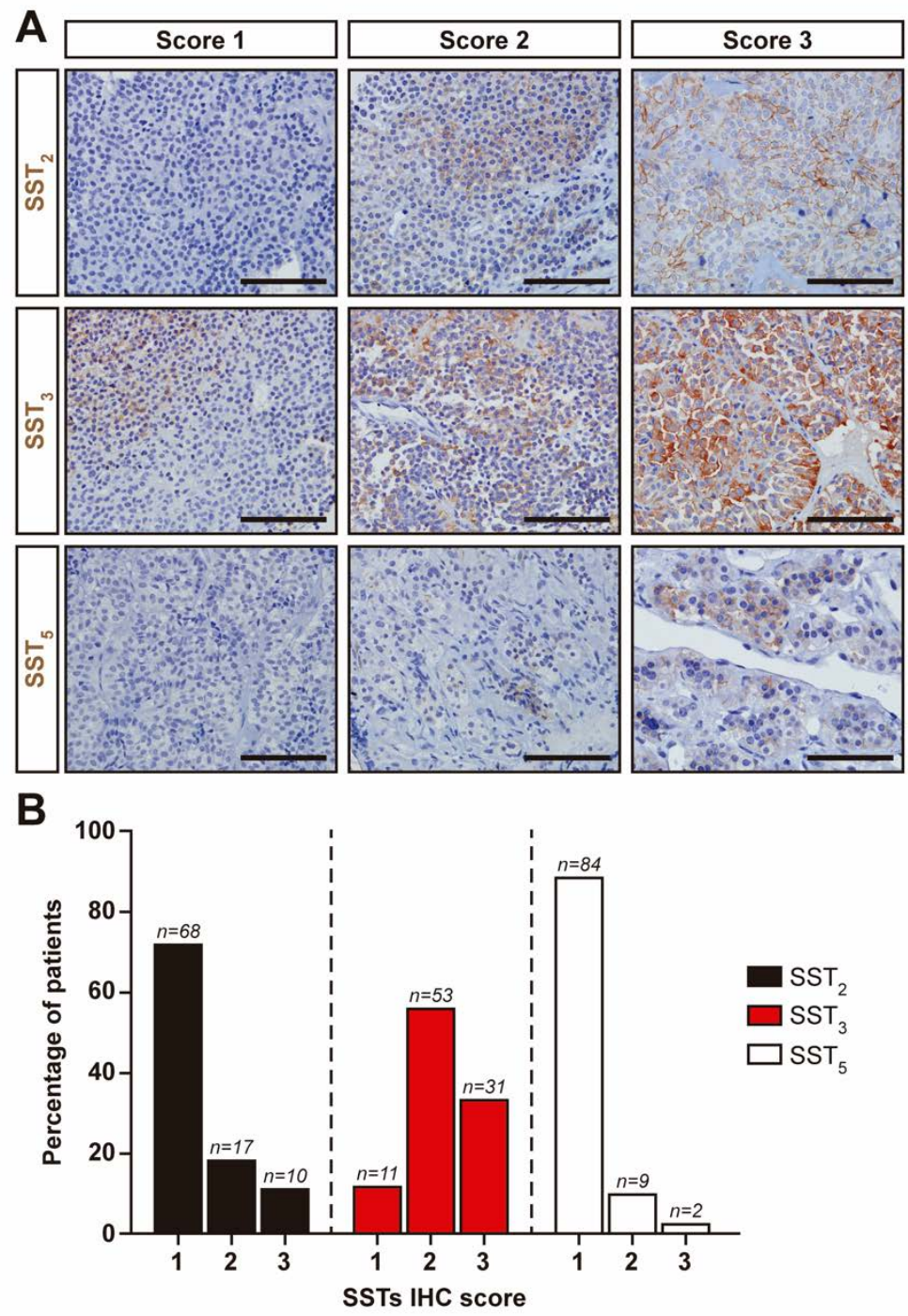

Figure 2. Immunohistochemical detection of somatostatin receptors (SSTs) in NFPTs assessed by immunohistochemistry. (A) Representative pictures of $\mathrm{SST}_{2}, \mathrm{SST}_{3}$ and $\mathrm{SST}_{5}$ immunohistochemical scores in NFPTs. Score 1, no or only cytoplasmic immunoreactivity; score 2, membranous immunoreactivity in less than $50 \%$ of cells; score 3 , membranous immunoreactivity in more than $50 \%$ of cells. Scale bar: $50 \mu \mathrm{m}$. (B) Percentage of NFPTs for immunohistochemistry (IHC) scores $\left(\mathrm{SST}_{2}, \mathrm{SST}_{3}\right.$ and $\left.\mathrm{SST}_{5}\right)$.

Most of the tumors expressed $\mathrm{SST}_{3}(88 \%$, Figure $2 \mathrm{~B})$. In contrast, the number of tumors with substantial expression of $\mathrm{SST}_{2}$ and $\mathrm{SST}_{5}$ was low (28 and $11 \%$, respectively). Gonadotropin-storing tumors and null cell tumors display a similar IHC score pattern, with a large number of tumors showing high $\mathrm{SST}_{3}$ scores but low $\mathrm{SST}_{2}$ and $\mathrm{SST}_{5}$ scores (Figure 2B). Surprisingly, no differences in $\mathrm{SST}_{2}, \mathrm{SST}_{3}$ and $\mathrm{SST}_{5}$ mRNA expression levels among their respective different IHC scores was found ( $p=0.06,0.16$ and 0.07 , respectively). Similar to what we observed when SSTs expression were examined by RT-qPCR, no differences were found for any SST between age, sex, tumor size, invasion, surgical cure or tumor regrowth and IHC scores.

\subsection{Evaluation of Molecular Markers Associated with Aggressive Features in NFPTs}

We sought to investigate the association of proliferation indexes, namely Ki-67 and p53, with aggressive features in our series of NFPTs. No association was found between Ki-67 levels and age, tumor size, invasion, surgical cure or tumor regrowth. Additionally, we did not find 
increased Ki-67 levels in giant (tumor size larger than $40 \mathrm{~mm}$ ) NFPTs. However, we need to note that most of NFPTs showed low Ki-67 levels with only four tumors displaying high Ki-67 levels (>3\%). Similar results were obtained with p53 immunohistochemistry (i.e., only four tumors also showed high p53 levels). Three of these tumors also displayed high Ki-67 levels and exhibited recurrence.

Next, we evaluated E-cadherin expression levels in NFPTs. Representative images of E-cadherin IHC semiquantitative scores in NFPTs are shown in Figure 3.

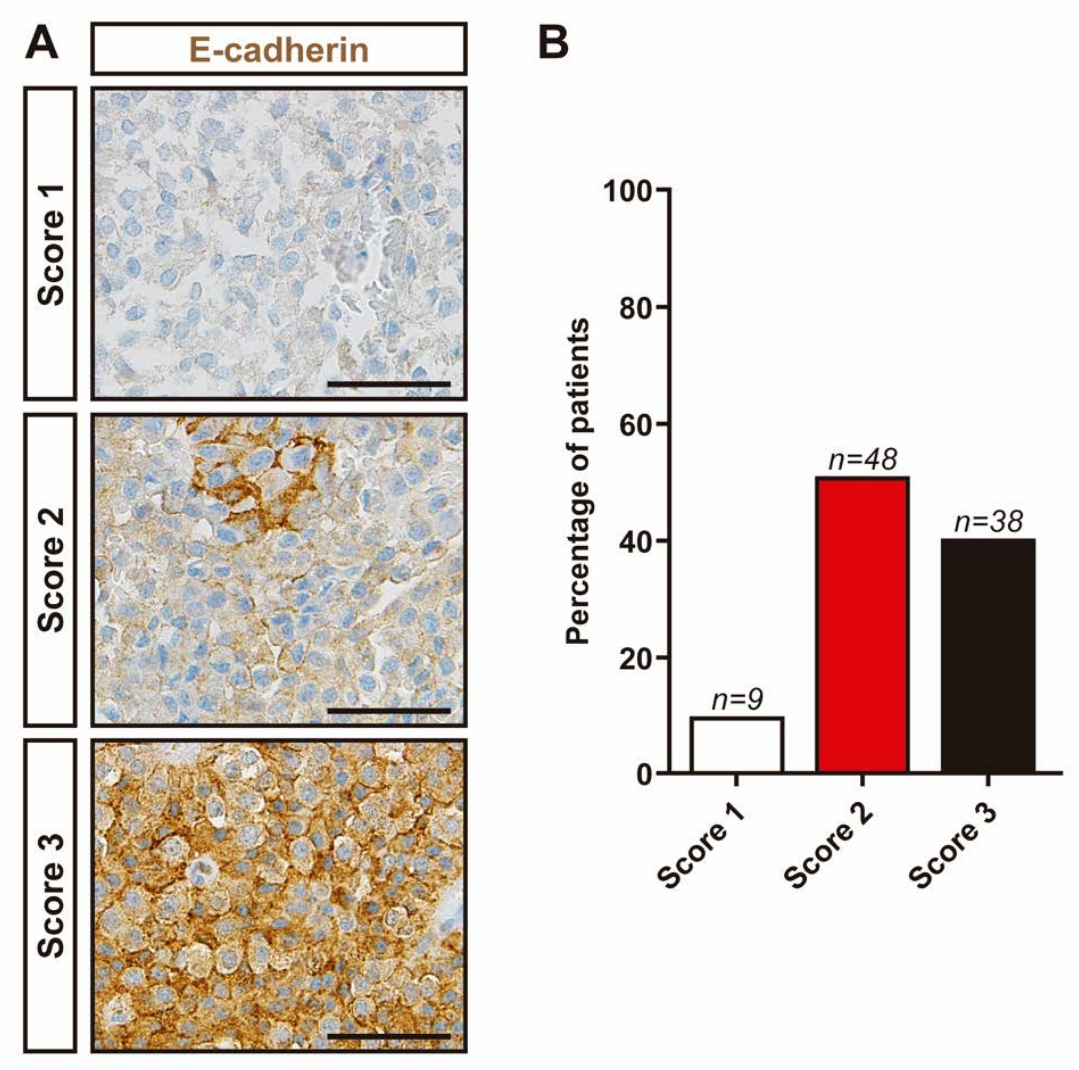

Figure 3. Accumulation of E-cadherin in NFPTs assessed by immunohistochemistry. (A) Representative pictures of E-cadherin immunohistochemical scores in NFPTs. Score 1, no or very low immunoreactivity; score 2 , membranous immunoreactivity in less than $50 \%$ of cells; score 3 , membranous immunoreactivity in more than 50\% of cells. Scale bar: $100 \mu \mathrm{m}$. (B) Percentage of NFPTs for IHC scores. Score 1: 9.47\%; score 2 : $50.52 \%$ and score $3: 40 \%$.

Nine tumors displayed no or extremely low membranous staining (Figure 3B). Forty-eight tumors displayed moderate membranous immunoreactivity (less than $50 \%$ of the tumor cells), while 38 tumors exhibited strong membranous immunoreactivity in more than $50 \%$ of the cells. However, we did not find statistically significant differences in tumor size, invasiveness and tumor regrowth among the three different E-cadherin IHC scores. Additionally, no differences in E-cadherin IHC score between gonadotropin-storing and null cell tumors were observed. Finally, no significant correlations between SSTs or DRDs expression and Ki-67, p53 index level or E-cadherin IHC score were observed.

\section{Discussion}

Here, we determined the expression profile of SSTs and DRDs in a large cohort of patients with NFPTs by RT-qPCR. $\mathrm{SST}_{3}$ was the predominant SST subtype expressed, followed by $\mathrm{SST}_{2}, \mathrm{SST}_{5}$ and $\mathrm{SST}_{1}$. Regarding DRDs expression, DRD2 was the predominant DRD subtype, followed by DRD4, DRD5, and DRD1. Our present findings compare favorably with previous studies using similar methodological approaches $[11,13,20,25,26]$. Our cohort of patients with NFPTs was composed of 
different histological subtypes, in similar proportions to what has been observed in previous large series of this type of tumors [27]. Thus, most of NFPTs were gonadotropin-storing tumors, followed by null cell tumors and SCTs. Only two plurihormonal and two silent GH-producing tumors were found in our cohort, confirming the rarity of these histological subtypes. The number of null cell tumors in our study may have been overestimated in our study as immunohistochemical expression of pituitary-specific transcription factors was not available. Nevertheless, the SSTs and DRDs expression pattern was similar between gonadotropin-storing and null cell tumors. In contrast, SCTs exhibited a distinct pattern of expression of SSTs and DRDs compared with the two other major histological subtypes. Thus, $\mathrm{SST}_{3}$ was the predominant SST subtype in SCTs, but levels were markedly lower compared to both gonadotropin-storing tumors and null cell adenomas. Similarly, even though DRD2 was the predominant DRD subtype in SCTs, expression levels were clearly lower than those found in both gonadotropin-storing tumors and null cell adenomas. In line with our data, two previous studies evaluating DRDs expression by RT-qPCR also reported lower DRD2 expression levels in SCTs compared to ACTH-negative pituitary adenomas $[13,28]$. The SSTs and DRDs expression patterns in SCTs are similar to those found in ACTH-secreting pituitary adenoma, as expected, since both tumor types share the same pituitary corticotroph lineage origin.

Dopamine agonists (DA) have been considered as a potential medical therapy for recurrent NFPTs $[7,8]$. Preclinical studies largely support this notion. Thus, DA inhibit gonadotropin secretion and cell growth of NFPTs in vitro $[29,30]$. The antitumor activity seems to involve both direct and indirect mechanisms such as antiangiogenic effects [29]. However, there is not enough solid evidence to recommend DA in routine clinical practice in this setting [7]. It has been suggested that response to DA treatment in NFPTs may be associated to DRD2 expression [31,32]. Based on this notion, our results would suggest that SCTs are less amenable for DA treatment. Nevertheless, it is important to note that a recent study could not find a relationship between the response to DA treatment and DRD2 levels in NFPTs [9] and thus, further studies are warranted to ascertain the efficacy of DA treatment for NFPTs and its relation to DRDs presence.

Our RT-qPCR results confirm previous studies that $\mathrm{SST}_{3}$ is, by far, the predominant SST expressed in NFPTs $[11,12,14,26]$. Since the correlation between SSTs mRNA and protein expression in pituitary adenomas is not always concordant $[18,33]$, we used IHC with commercial and widely validated antibodies to evaluate SSTs expression in NFPTs. Indeed, we found no correlation between in $\mathrm{SST}_{2}$, $\mathrm{SST}_{3}$ and $\mathrm{SST}_{5}$ mRNA expression levels and their respective IHC scores in NFPTs. This apparent discrepancy might be due to post-transcriptional regulation of SSTs protein synthesis among other biological processes. Differences inherent to each methodology could also account for this lack of correlation. In our case, SSTs scoring by IHC in NFPTs samples was carefully evaluated by a pathologist to ensure that only tumor tissue was analyzed. Nonetheless, IHC confirmed that $\mathrm{SST}_{3}$ was the SST most frequently expressed in NFPTs $(84 \%)$ followed by SST 2 and $\mathrm{SST}_{5}$. These results are very similar to a recent study evaluating SSTs expression by IHC [14]. In contrast, another study reported that $\mathrm{SST}_{2}$ was the most prevalent SST in NFPTs [15]. The discrepancies between this study and ours (and the study by Lee et al. [14]) may be due to differences in scoring criteria.

Preclinical studies have provided evidence that somatostatin analogues have antiproliferative effects in vitro in pituitary tumors, including NFPTs [34,35]. The antiproliferative activity of SSTs appears to be dependent on its receptor selectivity and thus, they might have different effects depending on the tumor subtype. In this regard, our results show that $84 \%$ of NFPTs displayed moderate or high $\mathrm{SST}_{3}$ expression. $\mathrm{SST}_{3}$ has been long considered a potential therapeutic target for medical treatment of NFPTs. Indeed, in a very recent collaborative study, we described that $\mathrm{SST}_{3}$ agonists inhibit cell growth in primary cell cultures from human NFPTs as well as in a preclinical mouse model [11]. Of note, it was found that the response to $\mathrm{SST}_{3}$ agonist treatment was associated to $\mathrm{SST}_{3}$ expression levels [11]. It would be very interesting to determine whether a similar correlation exists between $\mathrm{SST}_{3}$ expression and clinical response to $\mathrm{SST}_{3}$ agonists in patients with NFPTs. The clinical development of safe $\mathrm{SST}_{3}$-specific agonists is thus eagerly awaited to test whether this is an effective treatment 
for patients with NFPTs. An additional and attractive approach is combined therapy with DA and somatostatin analogues [7].

We found that a substantial proportion of NFPTs expressed a high degree of $\mathrm{SST}_{2}$ and $\mathrm{SST}_{5}$ expression ( $28 \%$ for $\mathrm{SST}_{2}$ and $11 \%$ for $\mathrm{SST}_{5}$ ). While the proportion might be relatively low, the finding that some NFPTs produce substantial amounts of $\mathrm{SST}_{2}$ and $\mathrm{SST}_{5}$ may have potential therapeutic implications concerning the use of somatostatin analogs targeting these specific SSTs. In this regard, specific antagonists for $\mathrm{SST}_{2}$ have been shown to inhibit cell proliferation in vitro, in primary cell cultures of NFPTs [34]. However, a SST 5 selective agonist actually increased NFPT cell viability [22]. Our results raise the question as to whether $\mathrm{SST}_{2}$ and $\mathrm{SST}_{5}$ agonists would be more effective in NFPTs expressing high levels of these SSTs. Proper studies evaluating different somatostatin analogues in NFPTs with different SSTs expression patterns would be very informative.

Our results demonstrate a wide heterogeneity in SSTs and DRDs expression in NFPTs, even within the different histological subtypes. There are likely multiple reasons underlying this variability and these are not well understood. However, the emerging picture of NFPTs (and PiTNETs in general) is that they are more complex at the molecular level than previously thought and that the current classification, based mainly on histological criteria, may be somewhat limited [36,37]. In this regard, a very recent study performed an unbiased, integrated pangenomic analyses in PiTNETs and found new tumor subtypes not previously characterized [38]. Indeed, the authors analyzed $\mathrm{SST}_{2}, \mathrm{SST}_{5}$ and DRD2 expression and observed substantial differences in expression levels among the newly identified PiTNETs subtypes [37]. Thus, the variability in SSTs and DRDs expression in NFPTs may reflect (at least, partially) the heterogeneous genetic and molecular landscape of these types of tumors.

In an attempt to evaluate potential histological markers of tumor behavior we studied in our large group of NFPTs several immunohistochemical markers that have been previously described to be associated with aggressive features of pituitary tumors. Thus, loss of membranous E-cadherin immunoreactivity has been reported to be associated with invasion in pituitary tumors in several studies, including our own [17,39-43]. Nevertheless, it is important to note that most of these studies were performed in functioning pituitary tumors. Actually, in the case of NFPTs, we found no association between E-cadherin accumulation and invasion, results that are in agreement with two previous studies [44,45]. Another study found lower E-cadherin levels in invasive NFPTs [41]. However, a different antibody and scoring IHC system was used in this study, thus making it difficult to compare the results.

The use of Ki-67 and p53 as prognostic markers of pituitary tumor behavior is controversial, with reports providing discordant results (recently reviewed in [3]). In particular, different cut-off values for Ki-67 levels have been proposed as predictors of pituitary tumor recurrence. Indeed, due to this variability, the 2017 WHO classification of pituitary tumors no longer defines a specific cut-off for Ki-67 levels. Nevertheless, the European Society of Endocrinology guidelines recommend Ki-67 index evaluation and p53 immunohistochemical evaluation when the Ki-67 index is higher than $3 \%$ but the interpretation of these results should be always considered within the clinical context of the individual patient [46]. In our study, the vast majority of NFPTs displayed low Ki-67 and p53 levels (less than 3\% of the cells) in agreement with previous reports [47-50]. Only four tumors out of $95(4.2 \%)$ showed proliferation levels higher than $3 \%$ (for each marker). This low number precludes attaining statistically significant results; however, we should note that all the NFPTs with high Ki-67 levels exhibited tumor progression. Interestingly, three of these tumors showed elevated p53 levels while only one tumor with low Ki-67 levels (out of 91) had high p53 expression levels.

In summary, our RT-qPCR and IHC analysis of a large number of NFPTs corroborates that $\mathrm{SST}_{3}$ and DRD2 are the predominant receptors in these tumors, although, no associations were found between SSTs and DRDs expression and any relevant clinical and molecular aggressiveness features of NFPTs. However, our data also revealed that a considerable proportion of NFPTs displayed appreciable levels of $\mathrm{SST}_{2}$ and $\mathrm{SST}_{5}$ expression, a finding with potential therapeutic implications for the use of $\mathrm{SST}_{2}$ 
and $\mathrm{SST}_{5}$ agonists for NFPTs treatment. Furthermore, a combined SSTs and DRDs expression signature may provide a rationale for the potential use of multimodal therapies, at least, in specific cases.

Author Contributions: Conceptualization, D.A.C. and A.S.-M.; Methodology, Á.F.-M., M.C.V.-B. and M.A.J.; Investigation, Á.F.-M., M.C.V.-B., M.A.J. and D.A.C.; Formal analysis: Á.F.-M., E.V.-M., M.C.V.-B., R.M.L.; M.A.J., J.P.C., D.A.C. and A.S.-M.; Resources, E.V.-M., E.D., P.R.-R., N.G.-H., A.M.-A., M.A.J., A.K., E.C.-V. and F.R.; Data curation, E.V.-M.; E.D.; P.R.-R.; N.G.-H., A.M.-A., M.A.J., A.K.; E.C.-V. and F.R.; Funding acquisition, R.M.L., J.P.C., D.A.C. and A.S.-M.; Supervision, D.A.C. and A.S.-M.; Writing-original draft, Á.F.-M., D.A.C. and A.S.-M.; Writing-review \& editing, Á.F.-M., R.M.L., J.P.C., D.A.C. and A.S.-M. All authors have read and agreed to the published version of the manuscript.

Funding: This work was supported by grants from the ISCIII-Subdirección General de Evaluación y Fomento de la Investigación co-funded with Fondos FEDER (PI16/00175 to A.S.-M. and D.A.C; PI16/00264 to R.M.L.), the Sistema Andaluz de Salud (A-0006-2017 and A-0055-2018 to A.S.-M, C-0015-2014 and RC-0006-2018 to D.A.C.), Ministerio de Ciencia, Innovación (BFU2016-80360-R to J.P.C.; PID2019-105564RB-I00 to R.M.L.) and Junta de Andalucía (BIO-0139 to J.P.C. and R.M.L.), and CIBERobn. CIBER is an initiative of Instituto de Salud Carlos III, Ministerio de Sanidad, Servicios Sociales e Igualdad, Spain. Part of the analyses included in this study was carried out within the REMAH ('Spanish molecular registry of pituitary adenomas') project, supported by Novartis Oncology as well as by the Andalusian and Spanish Societies of Endocrinology and Nutrition (SAEDYN and SEEN, respectively).

Acknowledgments: This research has been conducted using samples from the HUVR-IBiS Biobank (Andalusian Public Health System Biobank and ISCIII-Red de Biobancos PT17/0015/0041). The authors would like to thank Carolina Castilla and Fernando Carmona from HUVR-IBiS Biobank for their wonderful technical help. The authors are thankful to the donors for the human specimens used in this study.

Conflicts of Interest: This work was partly supported by a grant from Novartis Oncology Spain to A.S.-M. and D.A.C. Novartis Oncology did not have any role in the design, data collection and analysis of the study. The authors confirm that there are no other conflicts of interest regarding this study.

\section{References}

1. Melmed, S. Pituitary-tumor endocrinopathies. N. Engl. J. Med. 2020, 382, 937-950. [CrossRef] [PubMed]

2. Ntali, G.; Wass, J.A. Epidemiology, clinical presentation and diagnosis of non-functioning pituitary adenomas. Pituitary 2018, 21, 111-118. [CrossRef] [PubMed]

3. Dworakowska, D.; Grossman, A.B. Aggressive and malignant pituitary tumours: State-of-the-art. Endocr. Relat. Cancer 2018, 25, R559-R575. [CrossRef]

4. Øystese, K.A.; Evang, J.A.; Bollerslev, J. Non-Functioning pituitary adenomas: Growth and aggressiveness. Endocrine 2016, 53, 28-34. [CrossRef] [PubMed]

5. Zatelli, M.C. Pathogenesis of non-functioning pituitary adenomas. Pituitary 2018, 21, 130-137. [CrossRef]

6. Penn, D.L.; Burke, W.T.; Laws, E.R. Management of non-functioning pituitary adenomas: Surgery. Pituitary 2018, 21, 145-153. [CrossRef]

7. Greenman, Y. Management of endocrine disease: Present and future perspectives for medical therapy of nonfunctioning pituitary adenomas. Eur. J. Endocrinol. 2017, 177, R113-R124. [CrossRef]

8. Even-Zohar, N.; Greenman, Y. Management of NFAs: Medical treatment. Pituitary 2018, 21, $168-175$. [CrossRef]

9. Greenman, Y.; Cooper, O.; Yaish, I.; Robenshtok, E.; Sagiv, N.; Jonas-Kimchi, T.; Yuan, X.; Gertych, A.; Shimon, I.; Ram, Z.; et al. Treatment of clinically nonfunctioning pituitary adenomas with dopamine agonists. Eur. J. Endocrinol. 2016, 175, 63-72. [CrossRef]

10. Günther, T.; Tulipano, G.; Dournaud, P.; Bousquet, C.; Csaba, Z.; Kreienkamp, H.-J.; Lupp, A.; Korbonits, M.; Castaño, J.P.; Wester, H.-J.; et al. International union of basic and clinical pharmacology. CV. Somatostatin receptors: Structure, function, ligands, and new nomenclature. Pharmacol. Rev. 2018, 70, 763. [CrossRef]

11. Vázquez-Borrego, M.C.; Gupta, V.; Ibáñez-Costa, A.; Gahete, M.D.; Venegas-Moreno, E.; Toledano-Delgado, Á.; Cano, D.A.; Blanco-Acevedo, C.; Ortega-Salas, R.; Japón, M.A.; et al. Somatostatin receptor subtype-3 (SST3) peptide agonist shows antitumor effects in experimental models of nonfunctioning pituitary tumors. Clin. Cancer Res. 2020, 26, 957-969. [CrossRef]

12. Taboada, G.F.; Luque, R.M.; Bastos, W.; Guimarães, R.F.C.; Marcondes, J.B.; Chimelli, L.M.C.; Fontes, R.; Mata, P.J.P.; Filho, P.N.; Carvalho, D.P.; et al. Quantitative analysis of somatostatin receptor subtype (SSTR1-5) gene expression levels in somatotropinomas and non-functioning pituitary adenomas. Eur. J. Endocrinol. 2007, 156, 65-74. [CrossRef] [PubMed] 
13. Tateno, T.; Kato, M.; Tani, Y.; Oyama, K.; Yamada, S.; Hirata, Y. Differential expression of somatostatin and dopamine receptor subtype genes in adrenocorticotropin (ACTH)-secreting pituitary tumors and silent corticotroph adenomas. Endocr. J. 2009, 56, 579-584. [CrossRef]

14. Lee, M.; Lupp, A.; Mendoza, N.; Martin, N.; Beschorner, R.; Honegger, J.; Schlegel, J.; Shively, T.; Pulz, E.; Schulz, S.; et al. SSTR3 is a putative target for the medical treatment of gonadotroph adenomas of the pituitary. Endocr. Relat. Cancer 2015, 22, 111-119. [CrossRef] [PubMed]

15. Ramírez, C.; Cheng, S.; Vargas, G.; Asa, S.L.; Ezzat, S.; González, B.; Cabrera, L.; Guinto, G.; Mercado, M. Expression of Ki-67, PTTG1, FGFR4, and SSTR 2, 3, and 5 in nonfunctioning pituitary adenomas: A high throughput tma, immunohistochemical study. J. Clin. Endocrinol. Metab. 2012, 97, 1745-1751. [CrossRef] [PubMed]

16. Manojlovic-Gacic, E.; Engström, B.E.; Casar-Borota, O. Histopathological classification of non-functioning pituitary neuroendocrine tumors. Pituitary 2018, 21, 119-129. [CrossRef]

17. Venegas-Moreno, E.; Flores-Martinez, A.; Dios, E.; Vazquez-Borrego, M.C.; Ibañez-Costa, A.; Madrazo-Atutxa, A.; Japón, M.A.; Castaño, J.P.; Luque, R.M.; Cano, D.A.; et al. E-cadherin expression is associated with somatostatin analogue response in acromegaly. J. Cell. Mol. Med. 2019, 23, 3088-3096. [CrossRef]

18. Venegas-Moreno, E.; Vazquez-Borrego, M.C.; Dios, E.; Gros-Herguido, N.; Flores-Martinez, A.; Rivero-Cortés, E.; Madrazo-Atutxa, A.; Japón, M.A.; Luque, R.M.; Castaño, J.P.; et al. Association between dopamine and somatostatin receptor expression and pharmacological response to somatostatin analogues in acromegaly. J. Cell. Mol. Med. 2018, 22, 1640-1649. [CrossRef]

19. Luque, R.M.; Ibáñez-Costa, A.; Sánchez-Tejada, L.; Rivero-Cortés, E.; Robledo, M.; Madrazo-Atutxa, A.; Mora, M.; Álvarez, C.V.; Lucas-Morante, T.; Álvarez-Escolá, C.; et al. The molecular registry of pituitary adenomas (REMAH): A bet of Spanish endocrinology for the future of individualized medicine and translational research. Endocrinol. Nutr. 2016, 63, 274-284. [CrossRef]

20. Neto, L.V.; Machado, E.d.O.; Luque, R.M.; Taboada, G.F.; Marcondes, J.B.; Chimelli, L.M.C.; Quintella, L.P.; Niemeyer, P.; de Carvalho, D.P.; Kineman, R.D.; et al. Expression analysis of dopamine receptor subtypes in normal human pituitaries, nonfunctioning pituitary adenomas and somatotropinomas, and the association between dopamine and somatostatin receptors with clinical response to octreotide-LAR in acromegaly. J. Clin. Endocrinol. Metab. 2009, 94, 1931-1937. [CrossRef]

21. Ibáñez-Costa, A.; Gahete, M.D.; Rivero-Cortés, E.; Rincón-Fernández, D.; Nelson, R.; Beltrán, M.; de la Riva, A.; Japón, M.A.; Venegas-Moreno, E.; Gálvez, M.Á.; et al. In1-Ghrelin splicing variant is overexpressed in pituitary adenomas and increases their aggressive features. Sci. Rep. 2015, 5, 8714. [CrossRef] [PubMed]

22. Ibáñez-Costa, A.; Rivero-Cortés, E.; Vázquez-Borrego, M.C.; Gahete, M.D.; Jiménez-Reina, L.; Venegas-Moreno, E.; de la Riva, A.; Arráez, M.Á.; González-Molero, I.; Schmid, H.A.; et al. Octreotide and pasireotide (dis)similarly inhibit pituitary tumor cells in vitro. J. Endocrinol. 2016, 231, 135-145. [CrossRef] [PubMed]

23. Luque, R.M.; Ibáñez-Costa, A.; Neto, L.V.; Taboada, G.F.; Hormaechea-Agulla, D.; Kasuki, L.; Venegas-Moreno, E.; Moreno-Carazo, A.; Gálvez, M.Á.; Soto-Moreno, A.; et al. Truncated somatostatin receptor variant sst5TMD4 confers aggressive features (proliferation, invasion and reduced octreotide response) to somatotropinomas. Cancer Lett. 2015, 359, 299-306. [CrossRef] [PubMed]

24. Ben-Shlomo, A.; Cooper, O. Silent corticotroph adenomas. Pituitary 2018, 21, 183-193. [CrossRef]

25. Taboada, G.F.; Luque, R.M.; Neto, L.V.; Machado, E.d.O.; Sbaffi, B.C.; Domingues, R.C.; Marcondes, J.B.; Chimelli, L.M.C.; Fontes, R.; Niemeyer, P.; et al. Quantitative analysis of somatostatin receptor subtypes (1-5) gene expression levels in somatotropinomas and correlation to in vivo hormonal and tumor volume responses to treatment with octreotide LAR. Eur. J. Endocrinol. 2008, 158, 295-303. [CrossRef]

26. Greenman, Y.; Melmed, S. Expression of three somatostatin receptor subtypes in pituitary adenomas: Evidence for preferential SSTR5 expression in the mammosomatotroph lineage. J. Clin. Endocrinol. Metab. 1994, 79, 724-729. [CrossRef]

27. Saeger, W.; Lüdecke, D.K.; Buchfelder, M.; Fahlbusch, R.; Quabbe, H.-J.; Petersenn, S. Pathohistological classification of pituitary tumors: 10 years of experience with the German Pituitary Tumor Registry. Eur. J. Endocrinol. 2007, 156, 203-216. [CrossRef] 
28. Gabalec, F.; Beranek, M.; Netuka, D.; Masopust, V.; Nahlovsky, J.; Cesak, T.; Marek, J.; Cap, J. Dopamine 2 receptor expression in various pathological types of clinically non-functioning pituitary adenomas. Pituitary 2012, 15, 222-226. [CrossRef]

29. Gagliano, T.; Filieri, C.; Minoia, M.; Buratto, M.; Tagliati, F.; Ambrosio, M.R.; Lapparelli, M.; Zoli, M.; Frank, G.; degli Uberti, E.; et al. Cabergoline reduces cell viability in non functioning pituitary adenomas by inhibiting vascular endothelial growth factor secretion. Pituitary 2013, 16, 91-100. [CrossRef]

30. Florio, T.; Barbieri, F.; Spaziante, R.; Zona, G.; Hofland, L.J.; van Koetsveld, P.M.; Feelders, R.A.; Stalla, G.K.; Theodoropoulou, M.; Culler, M.D.; et al. Efficacy of a dopamine-somatostatin chimeric molecule, BIM-23A760, in the control of cell growth from primary cultures of human non-functioning pituitary adenomas: A multi-center study. Endocr. Relat. Cancer 2008, 15, 583-596. [CrossRef]

31. Su, Z.; Wang, C.; Wu, J.; Jiang, X.; Chen, Y.; Chen, Y.; Zheng, W.; Zhuge, Q.; Wu, Z.; Zeng, Y. Expression of dopamine 2 receptor subtype MRNA in clinically nonfunctioning pituitary adenomas. Neurol. Sci. 2012, 33, 275-279. [CrossRef] [PubMed]

32. Colao, A.; Ferone, D.; Lastoria, S.; Cerbone, G.; Di Sarno, A.; Di Somma, C.; Lucci, R.; Lombardi, G. Hormone levels and tumour size response to quinagolide and cabergoline in patients with prolactin-secreting and clinically non-functioning pituitary adenomas: Predictive value of pituitary scintigraphy with 123I-methoxybenzamide. Clin. Endocrinol. (Oxf.) 2000, 52, 437-445. [CrossRef] [PubMed]

33. Nielsen, S.; Mellemkjaer, S.; Rasmussen, L.M.; Ledet, T.; Olsen, N.; Bojsen-Møller, M.; Astrup, J.; Weeke, J.; Jørgensen, J.O. Expression of somatostatin receptors on human pituitary adenomas in vivo and ex vivo. J. Endocrinol. Investig. 2001, 24, 430-437. [CrossRef]

34. Florio, T.; Thellung, S.; Arena, S.; Corsaro, A.; Spaziante, R.; Gussoni, G.; Acuto, G.; Giusti, M.; Giordano, G.; Schettini, G. Somatostatin and its analog lanreotide inhibit the proliferation of dispersed human non-functioning pituitary adenoma cells in vitro. Eur. J. Endocrinol. 1999, 141, 396-408. [CrossRef] [PubMed]

35. Zatelli, M.C.; Piccin, D.; Bottoni, A.; Ambrosio, M.R.; Margutti, A.; Padovani, R.; Scanarini, M.; Taylor, J.E.; Culler, M.D.; Cavazzini, L.; et al. Evidence for differential effects of selective somatostatin receptor subtype agonists on alpha-subunit and chromogranin a secretion and on cell viability in human nonfunctioning pituitary adenomas in vitro. J. Clin. Endocrinol. Metab. 2004, 89, 5181-5188. [CrossRef]

36. Vandeva, S.; Daly, A.F.; Petrossians, P.; Zacharieva, S.; Beckers, A. Somatic and germline mutations in the pathogenesis of pituitary adenomas. Eur. J. Endocrinol. 2019, 181, R235-R254. [CrossRef]

37. Neou, M.; Villa, C.; Armignacco, R.; Jouinot, A.; Raffin-Sanson, M.-L.; Septier, A.; Letourneur, F.; Diry, S.; Diedisheim, M.; Izac, B.; et al. Pangenomic classification of pituitary neuroendocrine tumors. Cancer Cell 2020, 37, 123-134.e5. [CrossRef]

38. Beckers, A.; Aaltonen, L.A.; Daly, A.F.; Karhu, A. Familial isolated pituitary adenomas (FIPA) and the pituitary adenoma predisposition due to mutations in the aryl hydrocarbon receptor interacting protein (AIP) gene. Endocr. Rev. 2013, 34, 239-277. [CrossRef]

39. Elston, M.S.; Gill, A.J.; Conaglen, J.V.; Clarkson, A.; Cook, R.J.; Little, N.S.; Robinson, B.G.; Clifton-Bligh, R.J.; McDonald, K.L. Nuclear accumulation of E-cadherin correlates with loss of cytoplasmic membrane staining and invasion in pituitary adenomas. J. Clin. Endocrinol. Metab. 2009, 94, 1436-1442. [CrossRef]

40. Fougner, S.L.; Lekva, T.; Borota, O.C.; Hald, J.K.; Bollerslev, J.; Berg, J.P. The expression of E-cadherin in somatotroph pituitary adenomas is related to tumor size, invasiveness, and somatostatin analog response. J. Clin. Endocrinol. Metab. 2010, 95, 2334-2342. [CrossRef]

41. Zhou, W.; Song, Y.; Xu, H.; Zhou, K.; Zhang, W.; Chen, J.; Qin, M.; Yi, H.; Gustafsson, J.-A.; Yang, H.; et al. In nonfunctional pituitary adenomas, estrogen receptors and slug contribute to development of invasiveness. J. Clin. Endocrinol. Metab. 2011, 96, E1237-E1245. [CrossRef] [PubMed]

42. Qian, Z.R.; Sano, T.; Yoshimoto, K.; Asa, S.L.; Yamada, S.; Mizusawa, N.; Kudo, E. Tumor-specific downregulation and methylation of the CDH13 (H-cadherin) and CDH1 (E-cadherin) genes correlate with aggressiveness of human pituitary adenomas. Mod. Pathol. 2007, 20, 1269-1277. [CrossRef] [PubMed]

43. Chauvet, N.; Romanò, N.; Meunier, A.-C.; Galibert, E.; Fontanaud, P.; Mathieu, M.-N.; Osterstock, G.; Osterstock, P.; Baccino, E.; Rigau, V.; et al. Combining cadherin expression with molecular markers discriminates invasiveness in growth hormone and prolactin pituitary adenomas. J. Neuroendocrinol. 2016, 28. [CrossRef] [PubMed] 
44. Ongaratti, B.R.; Haag, T.; D’Ávila, M.F.; Trott, G.; Ferreira, N.P.; Rech, C.G.S.L.; Pereira-Lima, J.F.S.; da Costa Oliveira, M. Gene and protein expression of E-cadherin and NCAM markers in non-functioning pituitary adenomas. Ann. Diagn. Pathol. 2019, 38, 59-61. [CrossRef]

45. Yamada, S.; Ohyama, K.; Taguchi, M.; Takeshita, A.; Morita, K.; Takano, K.; Sano, T. A Study of the correlation between morphological findings and biological activities in clinically nonfunctioning pituitary adenomas. Neurosurgery 2007, 61, 580-584, discussion 584-585. [CrossRef]

46. Raverot, G.; Burman, P.; McCormack, A.; Heaney, A.; Petersenn, S.; Popovic, V.; Trouillas, J.; Dekkers, O.M.; European Society of Endocrinology. European Society of Endocrinology clinical practice guidelines for the management of aggressive pituitary tumours and carcinomas. Eur. J. Endocrinol. 2018, 178, G1-G24. [CrossRef]

47. Ogawa, Y.; Jokura, H.; Niizuma, K.; Tominaga, T. Mid-term prognosis of non-functioning pituitary adenomas with high proliferative potential: Really an aggressive variant? J. Neurooncol. 2018, 137, 543-549. [CrossRef]

48. Trouillas, J.; Roy, P.; Sturm, N.; Dantony, E.; Cortet-Rudelli, C.; Viennet, G.; Bonneville, J.-F.; Assaker, R.; Auger, C.; Brue, T. A new prognostic clinicopathological classification of pituitary adenomas: A multicentric case-control study of 410 patients with 8 years post-operative follow-up. Acta Neuropathol. 2013, 126, 123-135. [CrossRef]

49. Grimm, F.; Maurus, R.; Beschorner, R.; Naros, G.; Stanojevic, M.; Gugel, I.; Giese, S.; Bier, G.; Bender, B.; Honegger, J. Ki-67 labeling index and expression of p53 are non-predictive for invasiveness and tumor size in functional and nonfunctional pituitary adenomas. Acta Neurochir. (Wien) 2019, 161, 1149-1156. [CrossRef]

50. Zaidi, H.A.; Cote, D.J.; Dunn, I.F.; Laws, E.R. Predictors of aggressive clinical phenotype among immunohistochemically confirmed atypical adenomas. J. Clin. Neurosci. 2016, 34, 246-251. [CrossRef]

(C) 2020 by the authors. Licensee MDPI, Basel, Switzerland. This article is an open access article distributed under the terms and conditions of the Creative Commons Attribution (CC BY) license (http://creativecommons.org/licenses/by/4.0/). 